
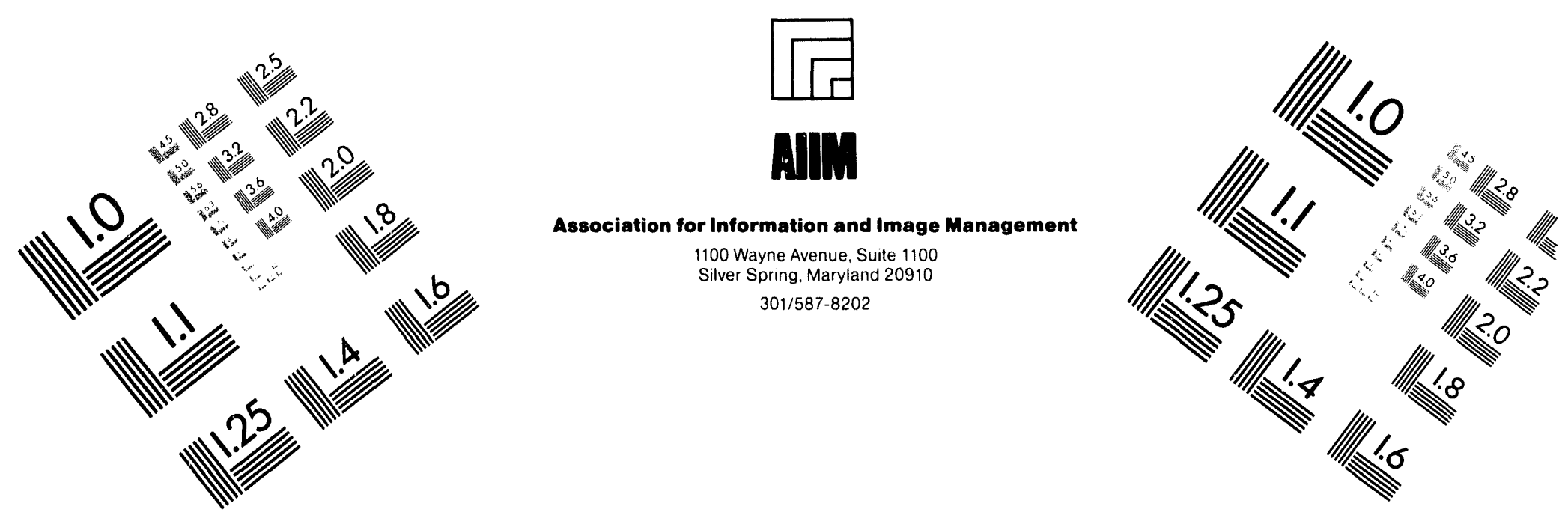

Centimeter

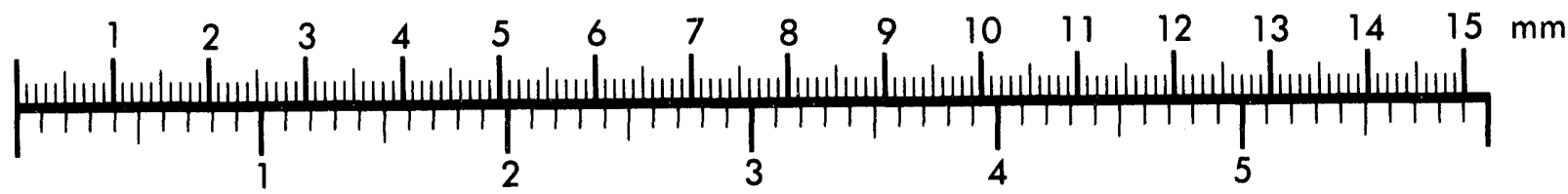

Inches
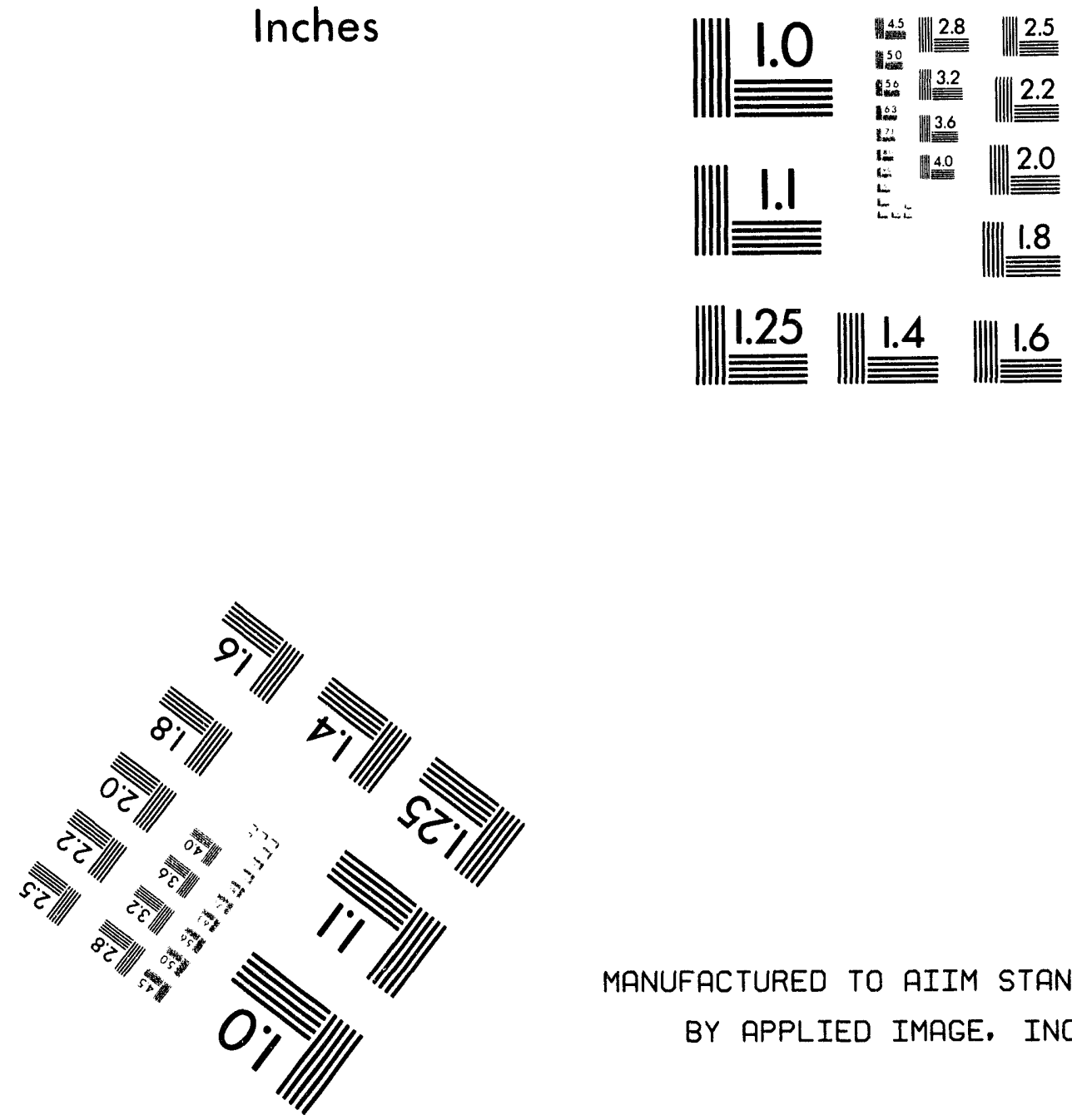

MANUFACTURED TO AIIM STANDARDS

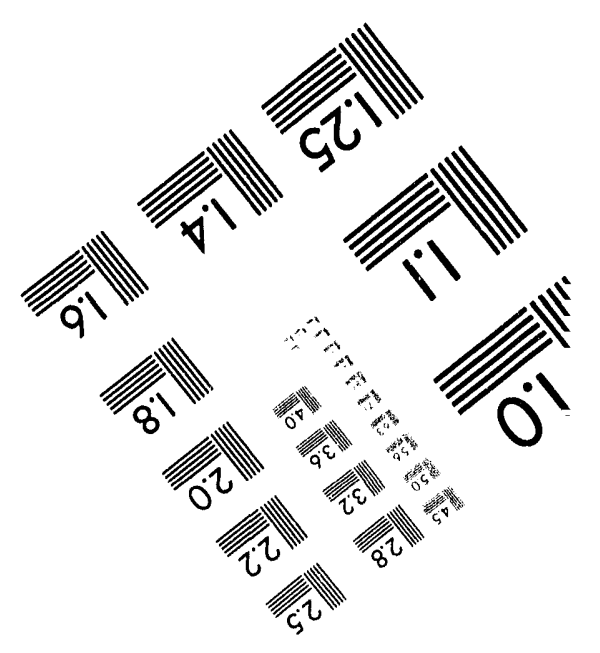




\section{$\ldots$}
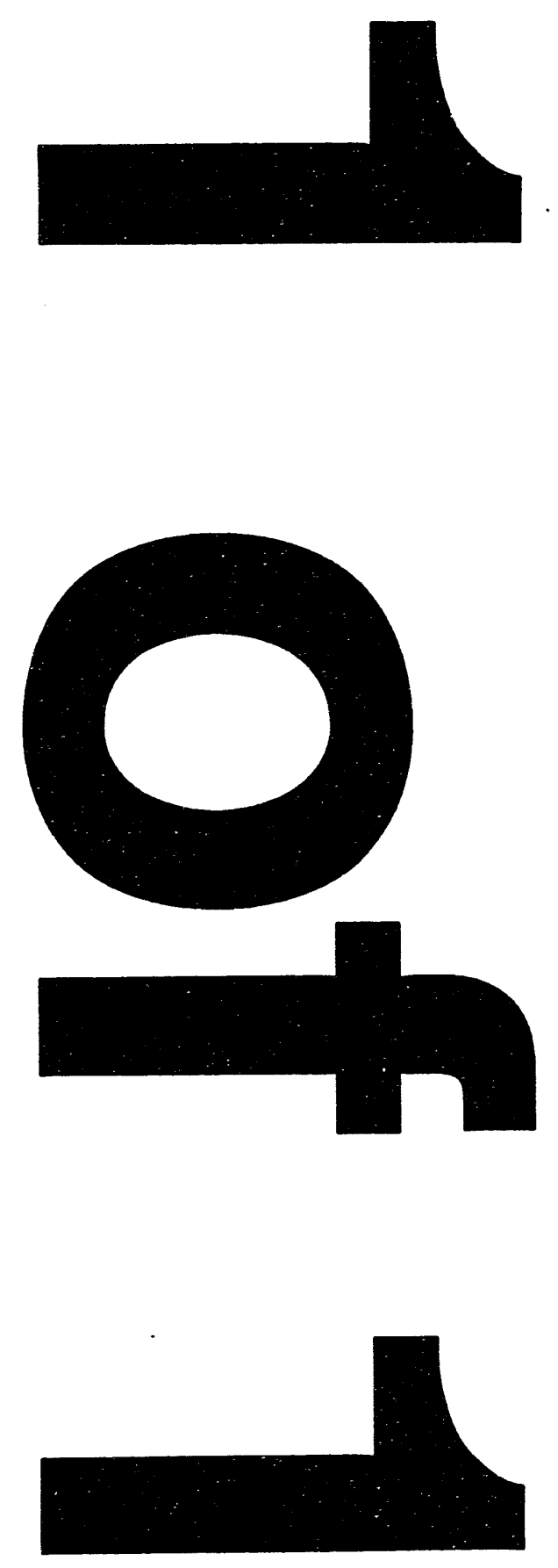


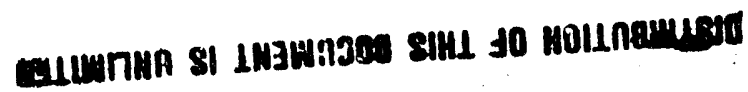

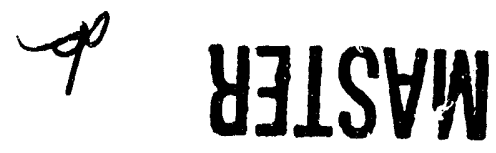

\section{sexo1 "unsny}

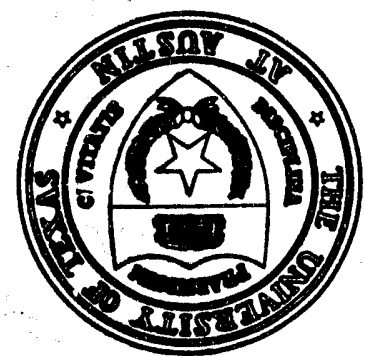

SVX]1 dO AIISE3AINก 캐

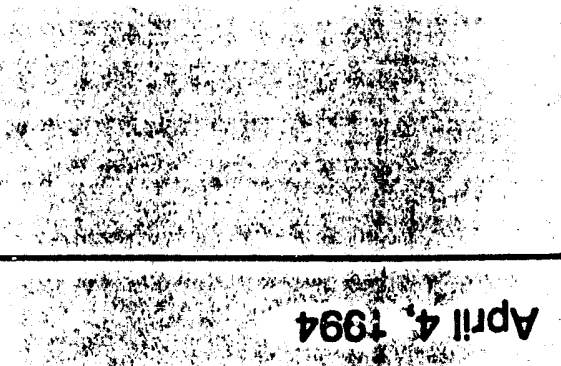

I!zedg-86t $10-d S-91502$ 'd'O 'Olned OES

Ined oBs ep epepissen!un eग!s! ep olnu!sul.

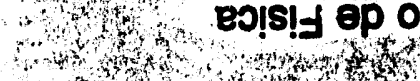

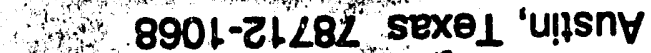

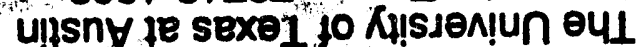

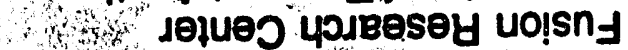

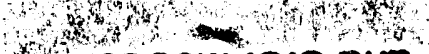

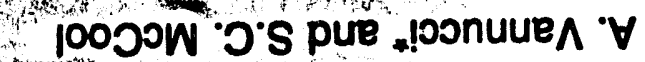

yвusyol n-1Xב1 ul sepow peyoo7

nysidy of

whing

$4+4$

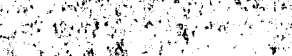

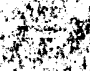

УבINZJ HOYYZSSIY NOISกJ 


\title{
LOCKED MODES IN TEXT-U TOKAMAK
}

\author{
A. Vannucci* and S.C. McCool \\ Fusion Research Center \\ The University of Texas at Austin \\ Austin, Texas - U.S.A., 78712 \\ *Instituto de Fisica \\ Universidade de Sao Paulo \\ Sao Paulo, C.P. 20516 - S.P.- 01498 - Brazil
}

\begin{abstract}
:
Locked mode coils for detecting radial magnetic field perturbations $\dot{\mathrm{B}}_{\mathrm{r}}$ were recently constructed and installed on the TEXT-U tokamak. The measured experimental signals showed that both minor and major disruptive instabilities were almost always preceded by a growth in $\dot{\mathrm{B}}_{\mathrm{r}}$. For some plasma discharges with long duration precursors, a mode lock occurs before the disruption takes place. However, detailed investigation showed that the modes were still rotating in the toroidal direction but with a very low frequency of about $50 \mathrm{~Hz}$. The results of the analysis done confirmed that the $m=1 / m=2$ mode coupling is the main triggering mechanism for the disruptions. Only after the coupling has taken place, when the frequency of the MHD activity measured with Mirnov coils has dropped from about $10 \mathrm{kHz}$ to near $5 \mathrm{kHz}$ and the characteristic deformation of the sawteeth has occurred, are fluctuating radial magnetic fields picked up by the locked mode coils.
\end{abstract}

\section{DISCLAIMER}

\footnotetext{
This report was prepared as an account of work sponsored by an agency of the United Sta is Government. Neither the United States Government nor any agency thereof, nor any of their employees, makes any warranty, express or implied, or assumes any legal liability or responsibility for the accuracy, completeness, or usefulness of any information, apparatus, product, or process disclosed, or represents that its use would not infringe privately owned rights. Reference herein to any specific commercial product, process, or service by trade name, trademark, manufacturer, or otherwise does not necessarily constitute or imply its endorsement, recommendation, or favoring by the United States Government or any agency thereof. The views and opinions of authors expressed herein do not necessarily state or reflect those of the United States Government or any agency thereof.
} 


\section{I - INTRODUCTION}

An increase of radial magnetic field perturbations during tokamak plasma discharges, usually related to slowed rotation of magnetic islands resulting from MHD mode locking, has already been reported to be correlated with several changes in the confined plasma [1-4]. In particular, before a major disruption, this increase may start either well before or almost simultaneously with the characteristic loop voltage spike. However, disruptions are not the only case where such precursors are observed. They are also associated with large amplitude quasi-stationary modes that follow the injection of a pellet, or occur after a large sawtooth collapse [1]. Furthermore, these perturbations of the radial magnetic field sometimes occur during the plasma current rise, lasting for a long period of time (as long as 3 seconds in JET). In some cases the plasma would subsequently disrupt, but in others, the mode would unlock allowing a normal discharge duration [5].

Generally, once the conditions for creating a locked mode are present in the plasma, degraded confinement is observed. The global stored energy decreases significantly as transport increases and even ECH efficiency is reduced. These effects have been attributed to a slowing of central plasma ion rotation [6].

Theoretical studies have attempted to explain how the locked modes are formed. The two most accepted models are: (1) the locked mode is a result of an interaction of MHD modes with the tokamak conducting vessel wall [7] and (2) magnetic error fields (either pre-existing or purposely imposed) can in some circumstances cause a torque on the plasma slowing plasma rotation on rational magnetic surfaces [8].

In TEXT-U a set of locked mode detection coils have recently been installed. The conditions in which locked modes were detected and the effects they produced on the plasma were investigated. The results of this study will be presented and discussed in this paper.

\section{II - DIAGNOSTIC SET-UP}

Two pairs of locked mode detecting coils have been constructed and installed on the TEXT-U tokamak. They were used along with other diagnostics to investigate how locked modes affect the confined plasma and to better understand how major disruptions are triggered. The coils of each pair were located $180^{\circ}$ apart toroidally (at tokamak ports 1 \& 8 and $4 \& 11$ ) and were constructed with 28 AWG magnet wire wound around the vacuum chamber radial ports. The coils have 12 turns each, corresponding to an effective area of about $2 \mathrm{~m}^{2}$. In order to provide good compensation for extraneous magnetic fields that would otherwise affect the experimental measurements, accurate alignment and precisely matched effective areas of the coils are required. These conditions were automatically satisfied by winding the coils around the tokamak ports, and therefore, no further signal compensation was necessary. The signals generated by the coils of each pair were directly subtracted, as shown in fig. 1, and were sampled at a frequency of $20 \mathrm{kHz}$. 
Limitations imposed by interference from other diagnostic systems prevented the two adjacent locked mode coils from having a toroidal angular separation of $90^{\circ}$, as would be desirable to measure both the sine and cosine components of the mode. Therefore, care must be taken in interpreting the phase difference of the experimentally measured signal oscillations, accounting for the toroidal positions of the locked mode coils.

\section{III - DISRUPTIONS}

It is common in TEXT-U discharges to observe an increase in the fluctuating radial magnetic field, measured by the locked mode coils, prior to the occurrence of a disruption. The time duration of these precursor oscillations varied significantly, from a few milliseconds to several tens of milliseconds. For nearly all the plasma pulses analyzed, the oscillations on the locked mode coil signals started at about the same time as an interaction between the $m=1$ and $m=2$ modes. This mode interaction, which is initiated by the growth of the $m=2$ resistive mode (apparently after it has reached a certain threshold amplitude), has been previously reported to be an important mechanism for triggering major disruptions in TEXT-U [9]. Analysis done on the relative timing of the event on the various diagnostic signals, and the way the plasma was affected, suggested that the presence of perturbed radial magnetic fields prior to major disruptions is more a consequence of the mode coupling than the actual trigger of the disruptive instability. The experimental results obtained, that will be presented in the following, will try to give some support to this statement.

\section{III.1 - Fast Disruptions}

Major disruptions in TEXT-U can occur on a very fast time scale. The discharge shown in fig. 2 is a typical example with $\mathrm{Ip} \approx 170 \mathrm{kA}$ (fig. 2a) disrupting at $\mathrm{t} \approx 266 \mathrm{~ms}$, when the average electron density reached its maximum (fig. 2b). The raw signal from one set of locked mode coils is shown in fig. 2c. Although noticeable MHD activity is detected by the internal Mirnov coils throughout the discharge (fig. 2d), only near the disruption time is a perturbed radial magnetic field detected by the locked mode coils. This discharge is shown on an expanded time scale, just before the disruption, in fig. 3. As was already mentioned, many major disruptions in TEXT-U are believed to be triggered by the growth of the $m=2$ mode which somehow couples to the $m=1$ mode causing the characteristic disturbance on the sawtooth oscillations. During this coupling phase, the frequency of the Mirnov oscillations almost always drops from $10-12 \mathrm{kHz}$ to $4-6 \mathrm{kHz}$. From this point on, the fluctuations observed on the various experimental signals exhibit the same frequency, which in many cases continues to decrease even further.

For the particular plasma pulse under discussion, the coupling is observed to begin at $\mathrm{t} \approx 263.5 \mathrm{~ms}$ (figs. $3 \mathrm{~b}, 3 \mathrm{c}$ and $3 \mathrm{~d}$ ). The frequency of the MHD oscillations, as shown in 
fig. 4, decreases from about $12 \mathrm{kHz}$ to approximately $5 \mathrm{kHz}$ during the last few milliseconds of the discharge. Only after this decrease in frequency occurs is the fluctuating radial magnetic field picked up by the locked mode coils. This is due to the conducting tokamak vacuum chamber which completely shields the locked mode coils from internal magnetic oscillations with frequencies above about $6 \mathrm{kHz}$. Note the 1/e attenuation frequency of the vacuum chamber was found experimentally to be $0.75 \mathrm{kHz}$ for $\mathrm{m}=2$, with the cutoff frequency proportional to $\mathrm{m}$. Fig. 3d shows that the oscillations on the locked mode coil signals rapidly grow in amplitude coincident with an increase in the $\mathrm{H}_{\alpha}$ signal (fig. 3e) and an inward plasma position shift (fig. 3f). Approximately two milliseconds later the plasma collapses.

\section{III.2 - Disruptions with long duration precursors}

The physical mechanism that triggers TEXT-U disruptions with long duration precursors apparently does not differ very much from the one responsible for fast disruptions. The same disturbance of sawtooth oscillations after an increase of MHD activity seen on Mirnov coils is observed. At the same time, oscillations on $\mathrm{H}_{\alpha}$ and other experimental signals are detected. The discharge shown in fig. 5 exemplifies these characteristics. The plasma horizontal position, after being deliberately shifted by a few centimeters with a prescribed waveform (fig. 5b), is believed to have caused the boundary of the plasma to interact with the limiter (figs. $5 \mathrm{c}$ and $5 \mathrm{~g}$ ), destabilizing the $\mathrm{m}=2$ mode (fig. 5d) and originating the minor and major disruptions occurring at $\mathrm{t} \approx 290 \mathrm{~ms}$ and $\mathrm{t} \approx 440$ ms, respectively. In both situations, the plasma current decreases slightly (fig. 5a), and the locked mode coils begin to detect the increasing radial magnetic field perturbation (fig. 5c). Also, large fluctuations appear on the $\mathrm{H}_{\alpha}$ signal (fig. 5f). Again, the oscillations on the various diagnostic signals all have the same frequency just prior to the disruption.

For most of the major disruptions with long duration precursor that were analyzed, typically the oscillation frequency decreases from $10-12 \mathrm{kHz}$ at the time of mode coupling, to 1-2 $\mathrm{kHz}$ when the plasma current collapses. Less frequently observed, however, are cases in which the mode seems to completely lock sometime before the negative loop voltage spike occurs. The plasma pulse shown in fig. 6 is one such case. In this discharge the MHD frequency before mode coupling was about $12 \mathrm{kHz}$ and continuously dropped till the plasma collapse took place. Looking at the soft $\mathrm{X}$-ray and $\dot{\mathrm{B}}_{\theta}$ signals in more detail (fig. $7 \mathrm{~b}$ and $7 \mathrm{c}$ ), one can see that there are virtually no oscillations on these signals during the last $10 \mathrm{~ms}$ of the discharge. This signature is usually interpreted as a complete cessation of magnetic island rotation. However, if the experimental signals from the two pairs of locked mode coils are integrated numerically and compared (figs. 7e and 7d), one can see that the modes are still rotating in the toroidal direction, but now with a frequency of only about 50 $\mathrm{Hz}$.

Interestingly, these principal characteristics were also observed during the minor disruption that occurred earlier in this discharge. As shown in fig. 8, after the usual disturbance of the sawtooth activity caused by the $m=2$ MHD mode at $t \approx 264$ ms (figs $8 b$ 
and $8 \mathrm{c}$ ), the plasma current started decreasing (fig. 8a) while the plasma horizontal position started moving to the inside (fig. 8d). The MHD frequency seen on the Mirnov coils (fig. $8 \mathrm{c}$ ) continuously decreased from $12 \mathrm{kHz}$ at $\mathrm{t} \approx 255 \mathrm{~ms}$ until the "locking" occurs at $\mathrm{t} \approx 282$ ms. At that point the frequency of the mode was as low as $40 \mathrm{~Hz}$, as estimated from the integrated locked mode coils signals (fig. 8f). During this period of time, increased hard Xray emission was observed (fig. 8h), despite a continuous movement of the plasma column away from the vacuum vessel vuter wall, toward the torus center (fig. $8 \mathrm{c}$ ).

Nevertheless, the plasma did not completely quench. At $t \approx 294 \mathrm{~ms}$, the plasma current (fig. 8a) and also the soft X-ray emission (fig. 8b) started increasing again. Soon afterwards, oscillations with increasing frequency are seen on the Mirnov coils (fig. 8c). Expanding the time scale of these experimental signals (fig. 9), it is apparent that sawteeth are observed again on the central soft X-ray signal (fig. 9a) even before the "unlocking" occurs (figs. $9 \mathrm{~b}$ and $9 \mathrm{c}$ ) at $\mathrm{t} \approx 298.2 \mathrm{~ms}$. This indicates that after the minor disruption $\mathrm{at} t \approx$ 292 ms takes place, the size of the $q=2$ island may have decreased significantly allowing the recovery of the inner region of the plasma column. Only afterwards, the plasma within the $q=2$ magnetic surface region would begin rotating faster, possibly due to a change in the radial electric field, and oscillations with increasing frequency would consequently be measured by the Mirnov coils.

The plasma pulse shown on fig. 10 is another example of mode locking which is preceded by long duration precursors. In this case, however, the $m=1$ and $m=2$ mode interaction has occurred during the plasma current ramp phase (fig. 10a). Soon after the plasma current has reached a plateau, about $30 \mathrm{~ms}$ before the end of the discharge, the oscillations on the soft $\mathrm{X}$-ray and $\dot{\mathrm{B}}_{\theta}$ signals disappear (figs. $10 \mathrm{~b}$ and $10 \mathrm{c}$ ). During this interval the cylindrical safety factor is about 2.7. While "locked", several partial disruptions occur before the plasma collapses. Oscillations are observed on $\dot{\mathrm{B}}_{\theta}$ and $\mathrm{H}_{\alpha}$ (figs. 10c and $10 \mathrm{e}$ ), near the time of these partial disruptions, indicating perhaps that at least one $m \geq 3$ mode is still rotating.

\section{V - CONFINEMENT DEGRADATION}

Fig. 11 shows a plasma discharge that did not end in a major disruption, but which suffered a mild partial disruption at $\mathrm{t} \approx 177 \mathrm{~ms}$ as a result of the mode interaction that occurred earlier. Coincident with the rapid growth of MHD activity (fig. 11b), a relatively small decrease in central soft X-ray emission is observed (fig. 11c) and a slight radial magnetic field perturbation is detected by the locked mode coils (fig. 11d). Although no change was observed in the loop voltage (fig. 11e), increased $\mathrm{H}_{\alpha}$ emission was detected

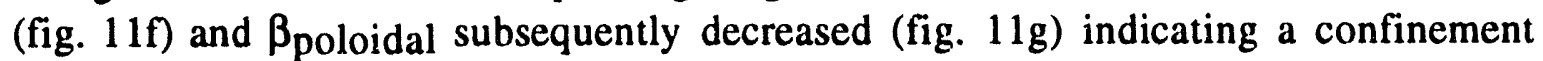
degradation. Details of this pulse, at the time of the mode interaction, are shown in fig. 12 . Note that the low frequency oscillations on the internal Mirnov coil signal (fig. 12b) are just spurious pickup from external power supplies. The MHD frequency for particular time intervals before $(\approx 12 \mathrm{kHz})$, during $(\approx 7 \mathrm{kHz})$ and after MHD mode coupling $(\approx 6 \mathrm{kHz})$ are shown in fig. 13. Note the frequency remains near $6 \mathrm{kHz}$ till the end of the discharge. 


\section{VI - CONCLUSIONS}

The measurement of perturbed radial magnetic fields using the recently installed locked mode coils has proven to be an important tool for investigating disruptions in TEXT-U plasmas. $\dot{\mathrm{B}}_{\mathrm{r}}$ signals with increasing amplitude were detected prior to most of the disruptions analyzed. Because of the $6 \mathrm{kHz}$ cutoff limit of the conducting vacuum chamber, the coils were able to measure the presence of fluctuating radial magnetic fields only after the characteristic $m=2 / m=1$ mode coupling has occurred and the frequency of the Mirnov signals has dropped from approximately $10-12 \mathrm{kHz}$ to $5-6 \mathrm{kHz}$. These oscillations on the locked mode coil signals, a precursor to disruptions, were observed to last from a few milliseconds to several tens of milliseconds.

For some discharges, however, the oscillations on the Mirnov coil and soft X-ray signals disappeared prior to the plasma disruption. This data, in conjunction with results obtained in other tokamaks, could be interpreted as a stopping of rotation of the magnetic islands associated with the MHD modes. However, the signals obtained with the locked mode coils show this is not the case, at least for TEXT-U plasmas. Even after the soft Xray and $\dot{\mathrm{B}}_{\theta}$ oscillations disappear, the modes still rotate in the toroidal direction but with very low frequency, estimated to be around $50 \mathrm{~Hz}$. This "mode locking" was observed both for partial and major disruptions.

\section{Acknowledgments}

The authors would like to thank Dr. Alan Wootton for many useful suggestions and helpful discussions. The first author is also very grateful to all of the FRC staff, in particular to Dr. Emilia Solano and Dr. William Rowan. This work was performed under U.S. Dept. of Energy grant DE-FG03-94ER54241 and with financial support from from FAPESP - Fundacao de Amparo a Pesquisa do Estado de Sao Paulo.

\section{References}

[1] - SNIPES, J.A., CAMPBELL, D.J., et al. - Nucl. Fusion 28 (1988) 1085.

[2] - HENDER T.C., FITZPATRICK, R., et al. - Nucl. Fusion 32 (1992) 2091.

[3] - SCOVILLE J.T., La HAYE R.J., et. al. - Nucl. Fusion 31 (1991) 875.

[4] - KAYE, S.M., JAHNS, G.L., et. al. - Nucl. Fusion 28 (1988) 1963.

[5] - WESSON, J.A., GILL, R.D., et al. - Nucl. Fusion 29 (1989) 641. 
[6] - HAYE, R.J., HYATT, A.W., et al. - Nucl. Fusion 32 (1992) 2119.

[7] - NAVE, M.F.F., WESSON, J.A. - Nucl. Fusion 30 (1990) 2575.

[8] - FITZPATRICK, R., HENDER, T.C. - Phys. Fluids B3 (1991) 2230.

[9] - VANNUCCI, A., McCool, S.C. - "Major Disruptions in TEXT-U Tokamak", Fusion Research Report FRCR \#431, University of Texas at Austin (1993). 


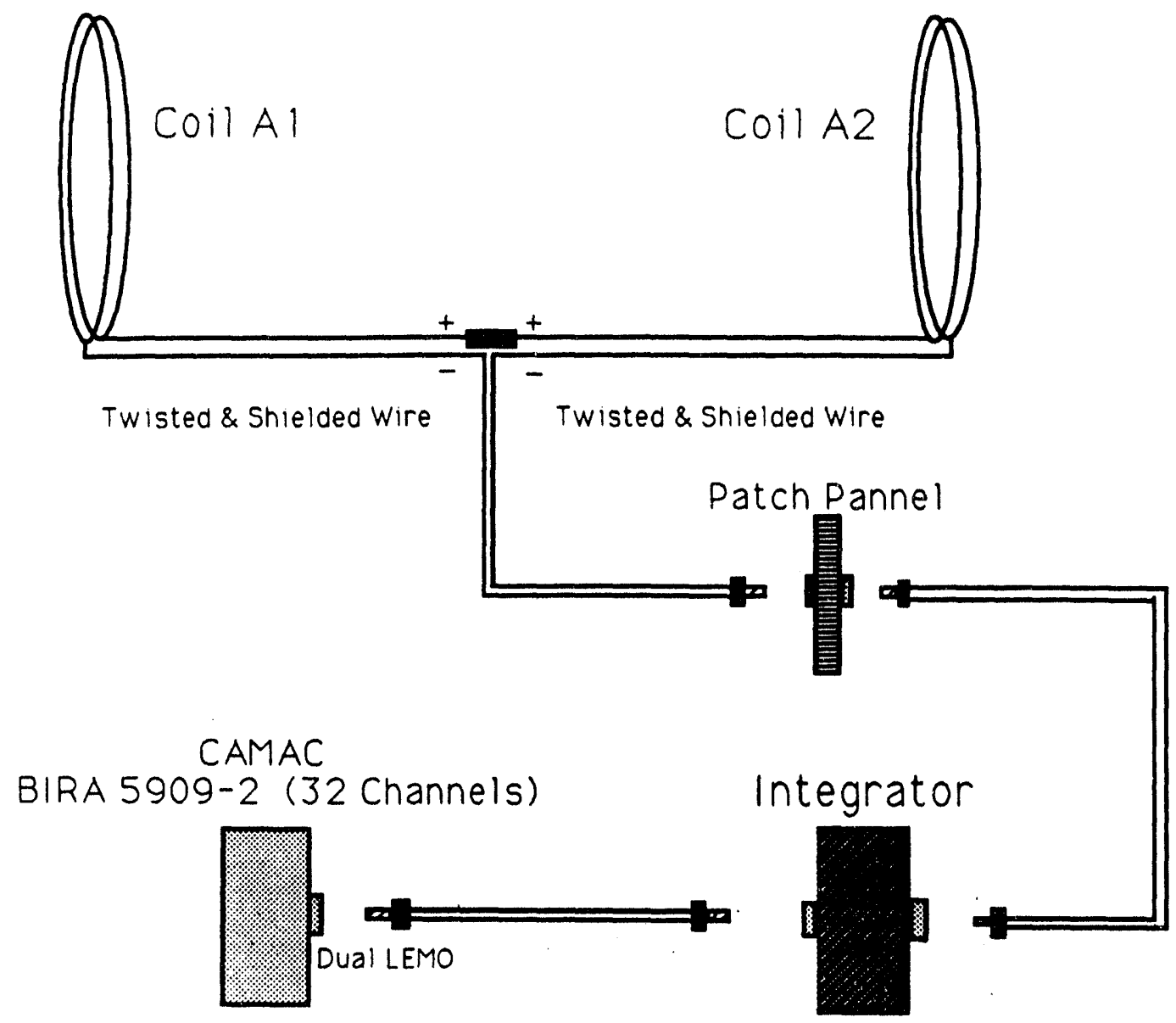

Fig. 1 


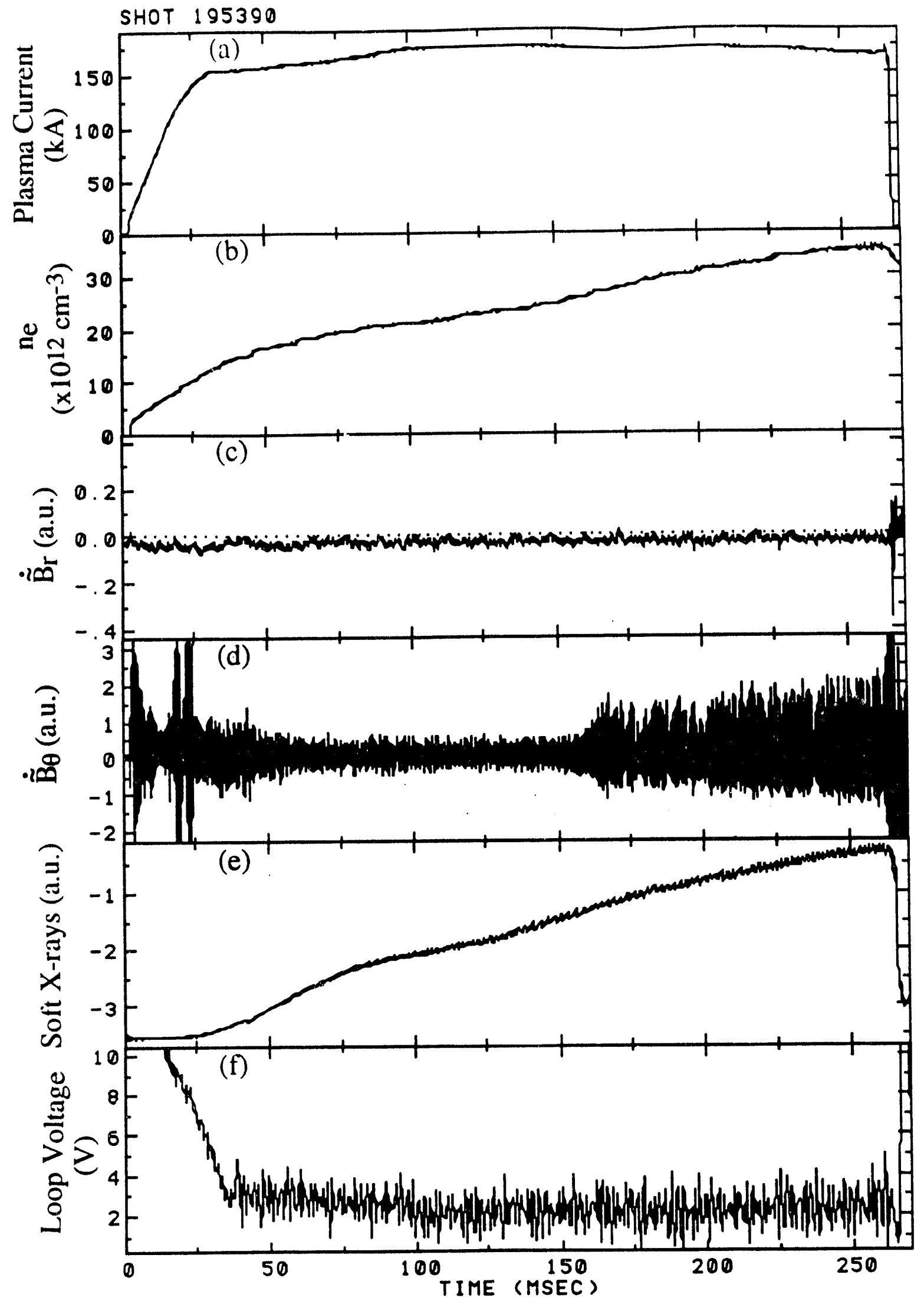

Fig. 2 


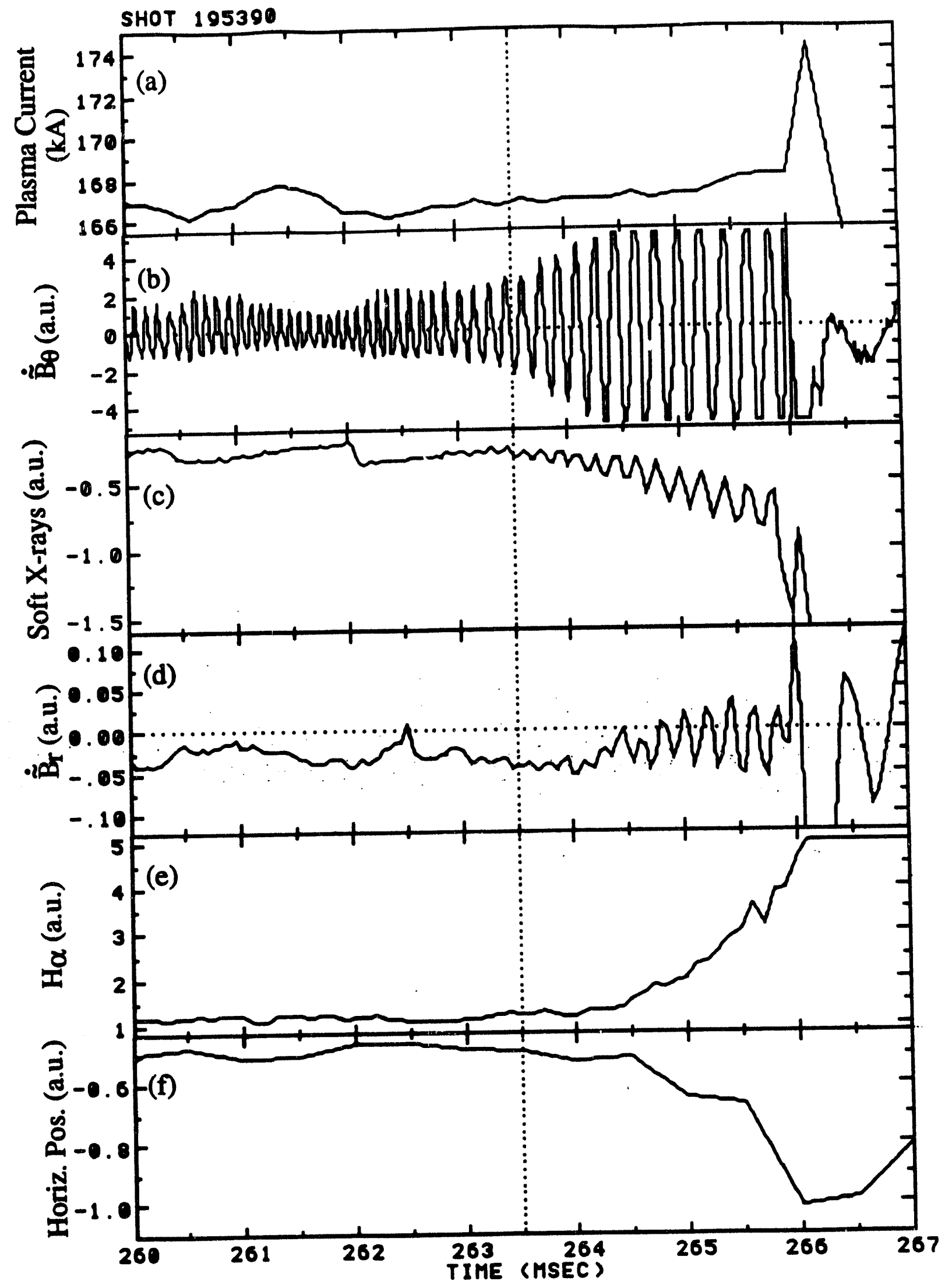

Fig. 3 

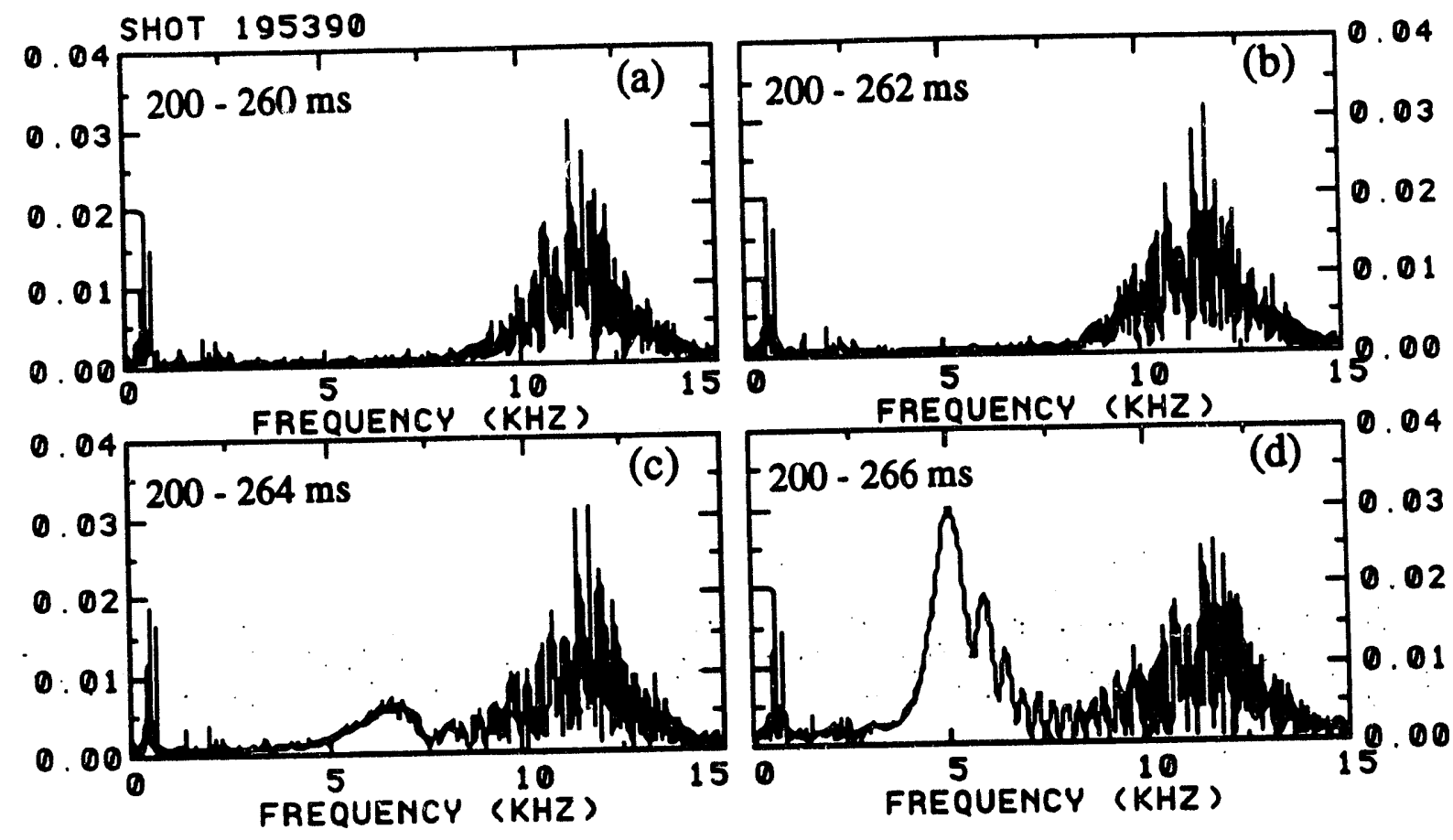

Fig. 4 


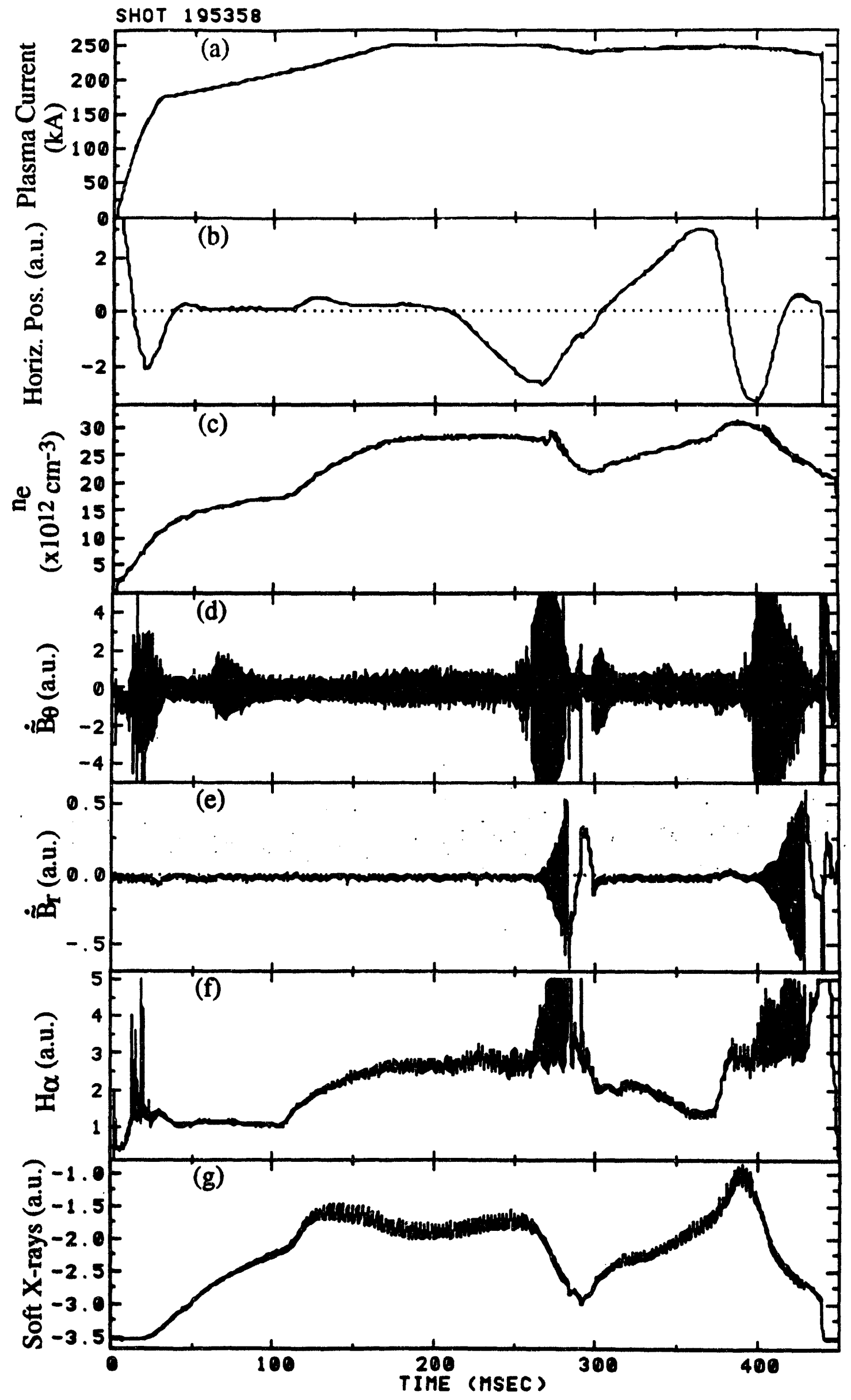

Fig. 5 

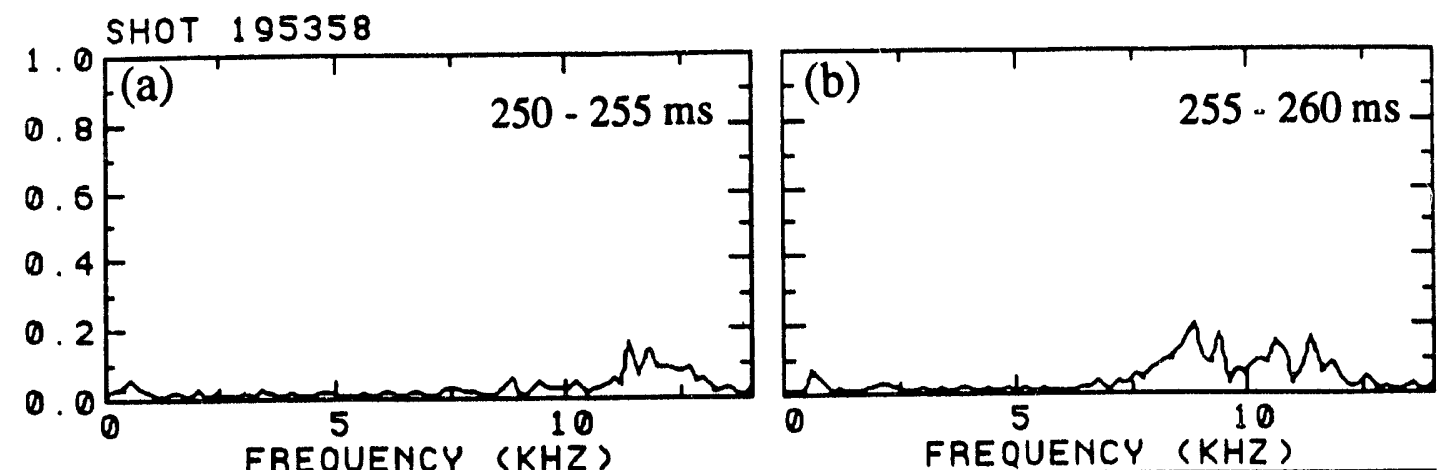

1.0
0.8
0.6
0.4
0.2
0.0
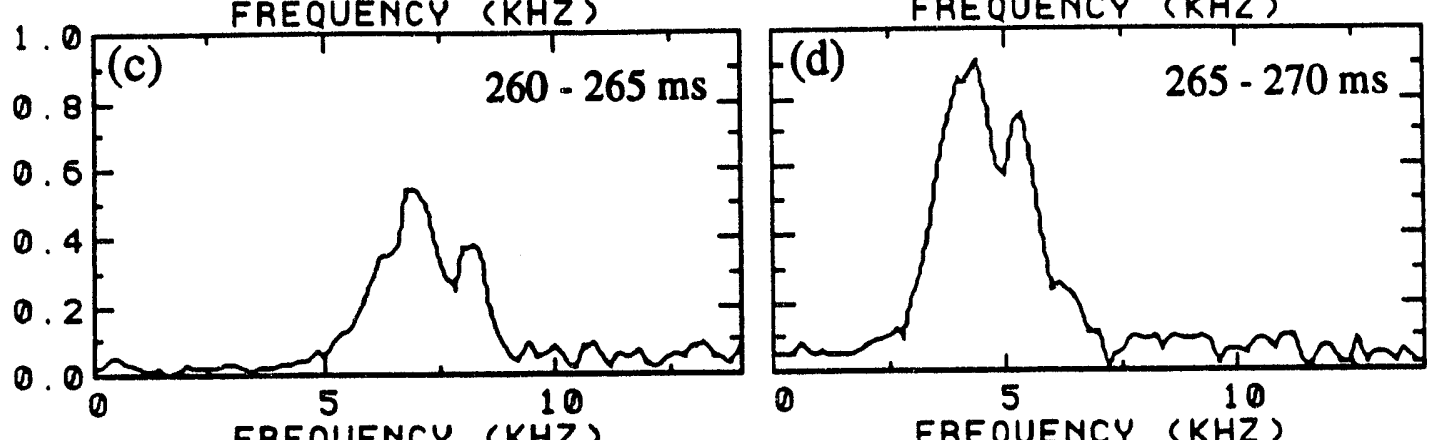

1.0

0.8

0.6

0.4

0.2

0.0
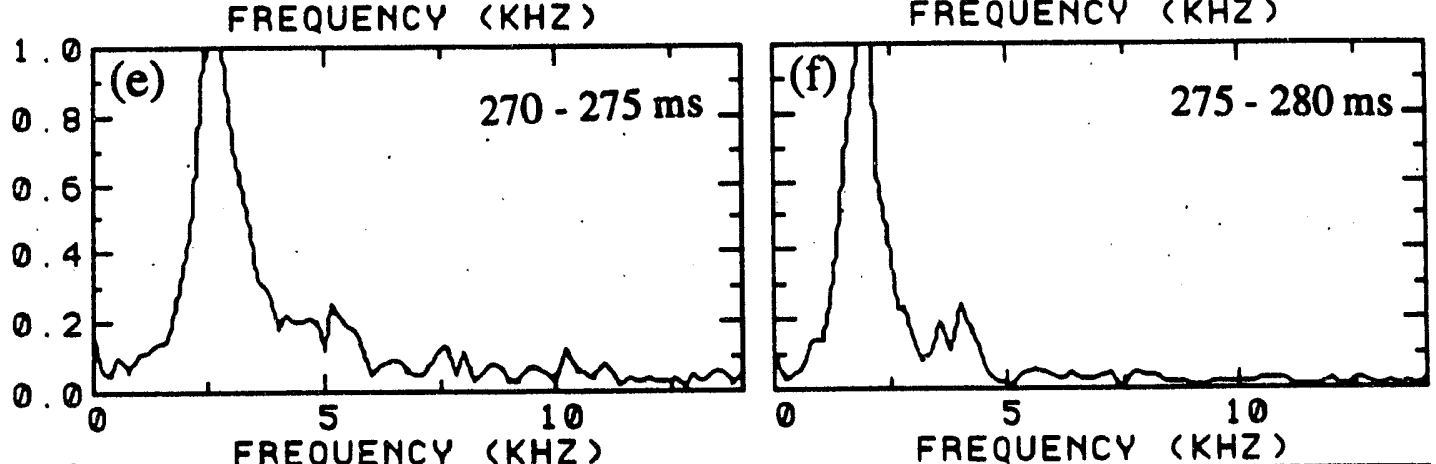

1.0

0.8

$0: 0$

0.4

0.2

0.0

1. 0

FREQUENCY ( $K H Z$ )

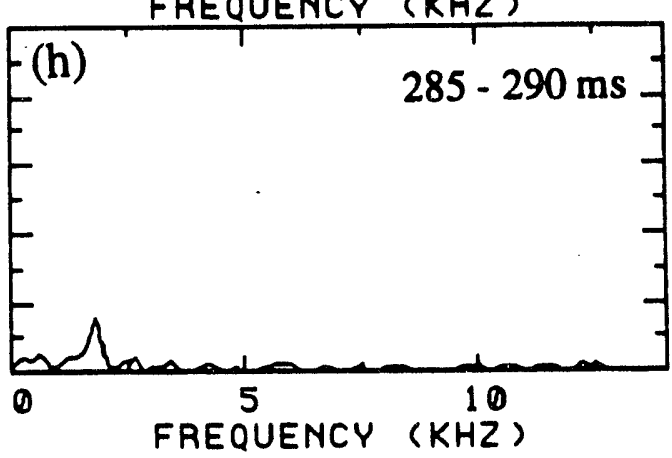

1.0

0.8

0.6

0.4

0.2

0.0

Fig. 6 


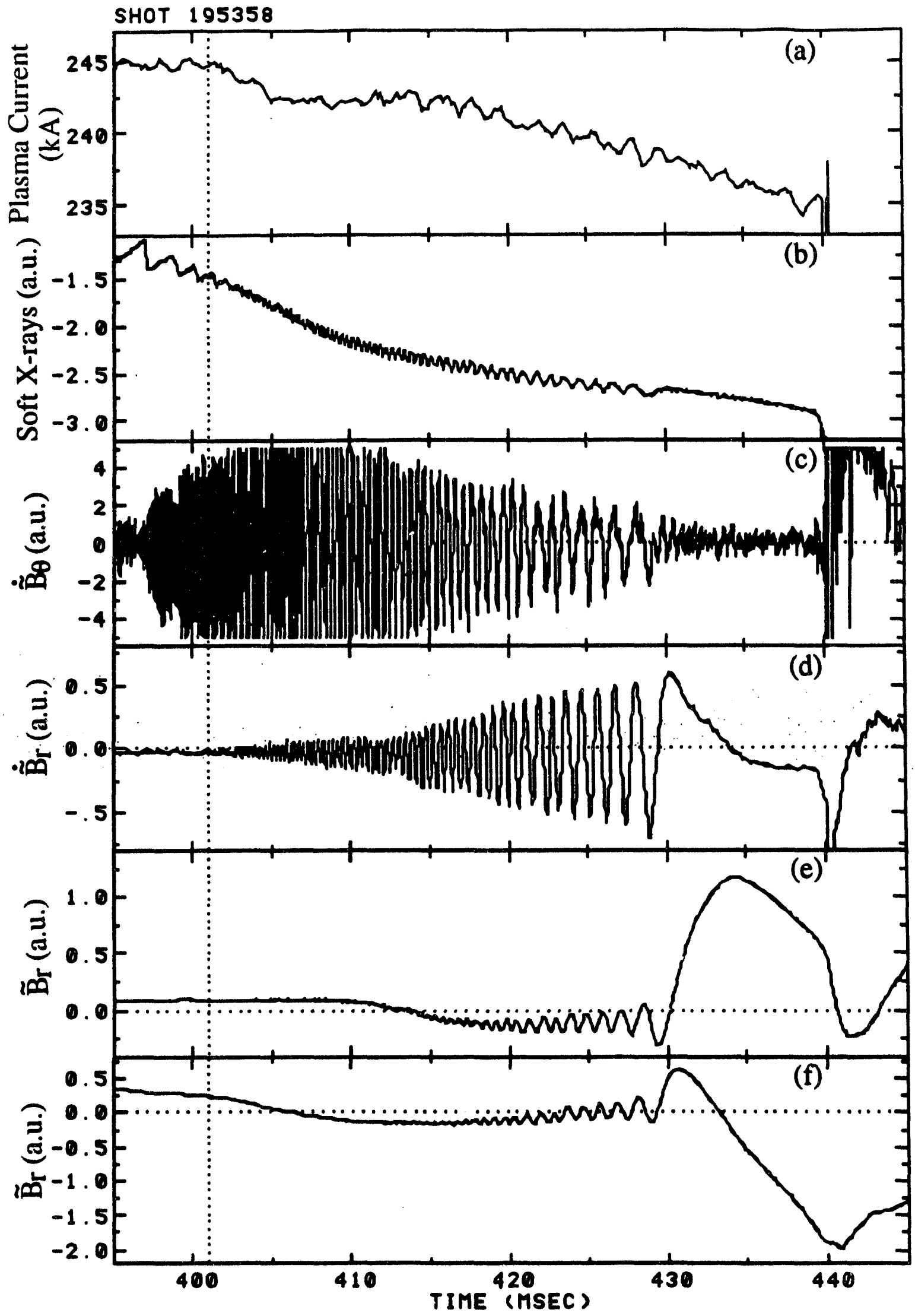

Fig. 7 


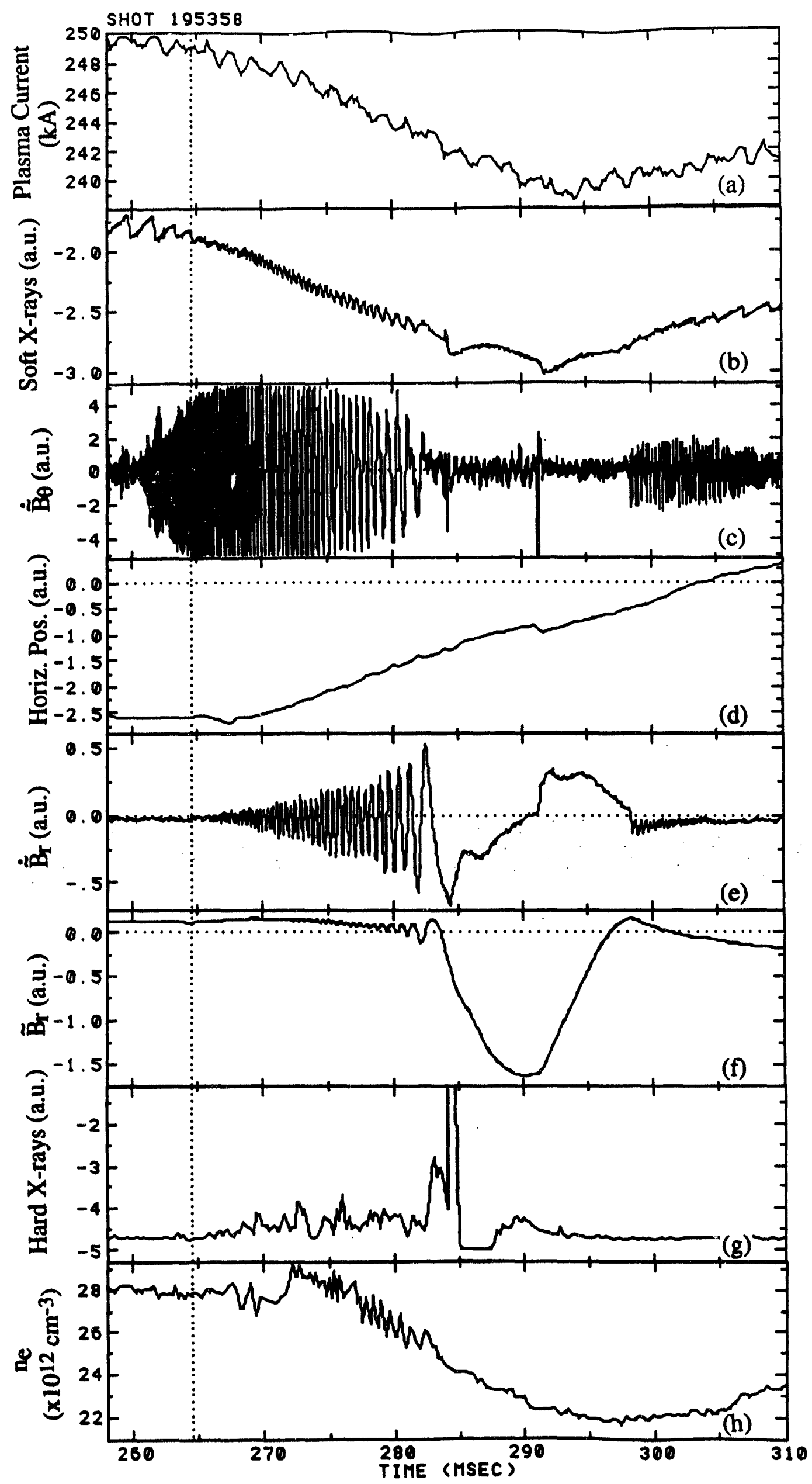

Fig. 8 


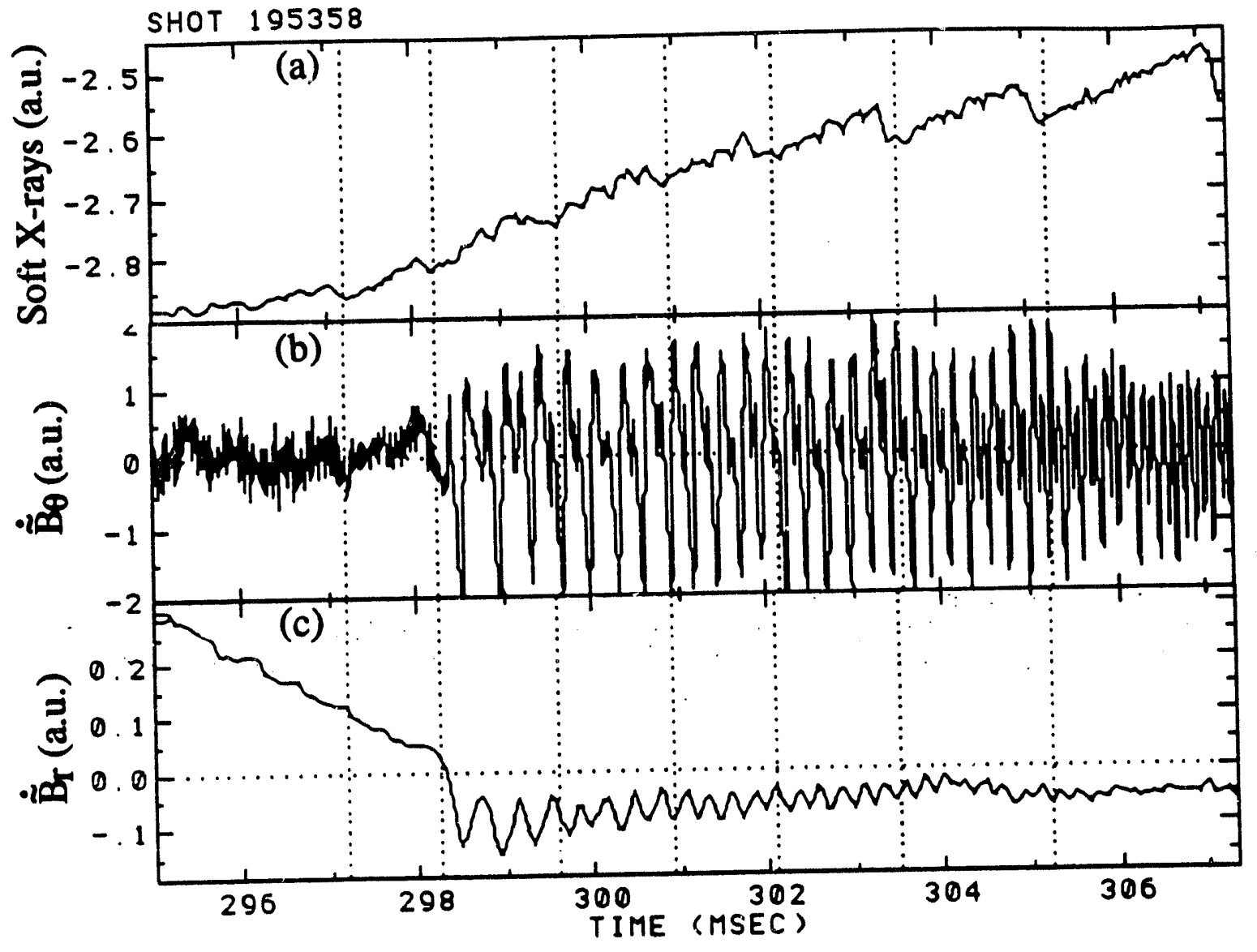

Fig. 9 


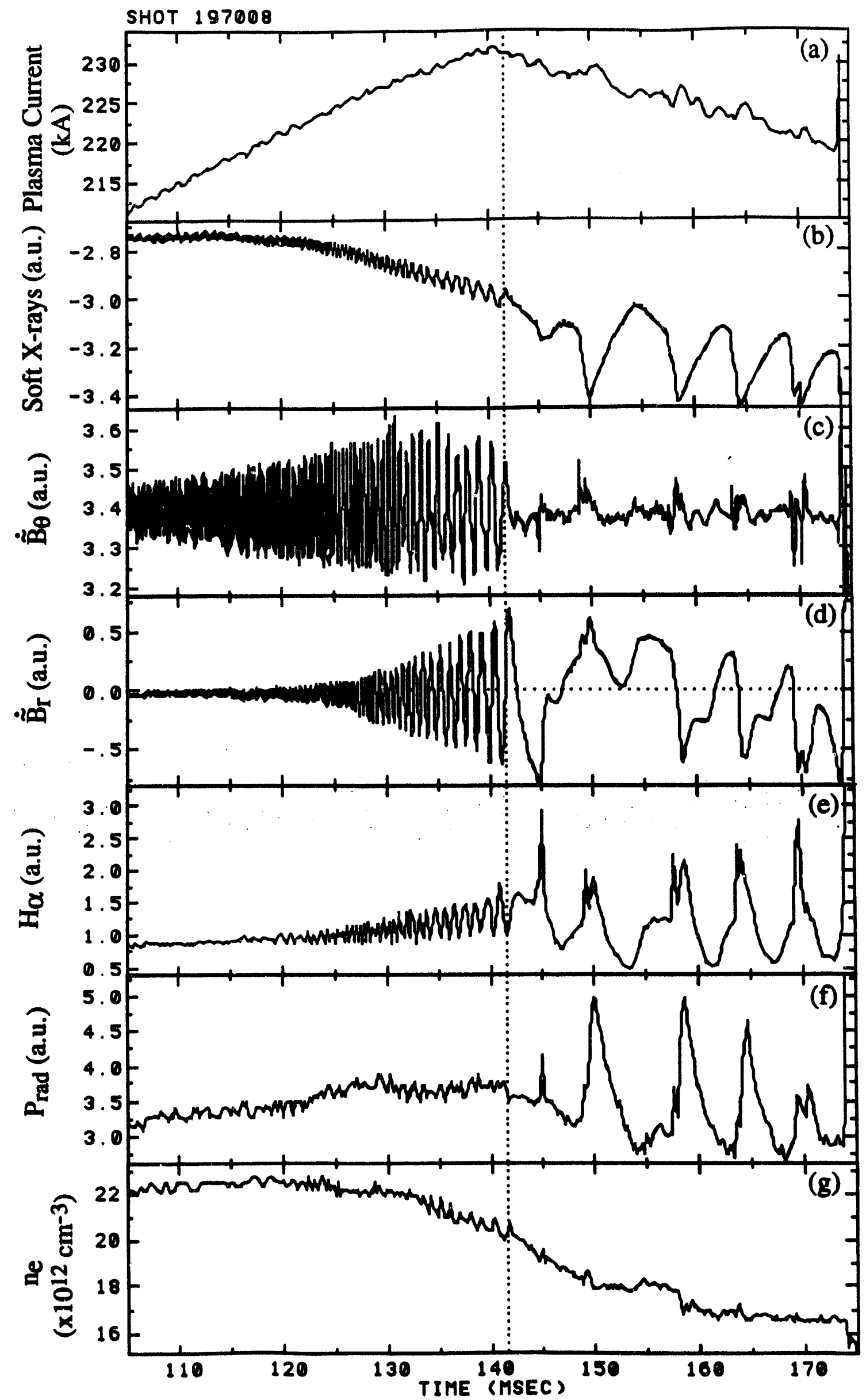

Fig. 10 


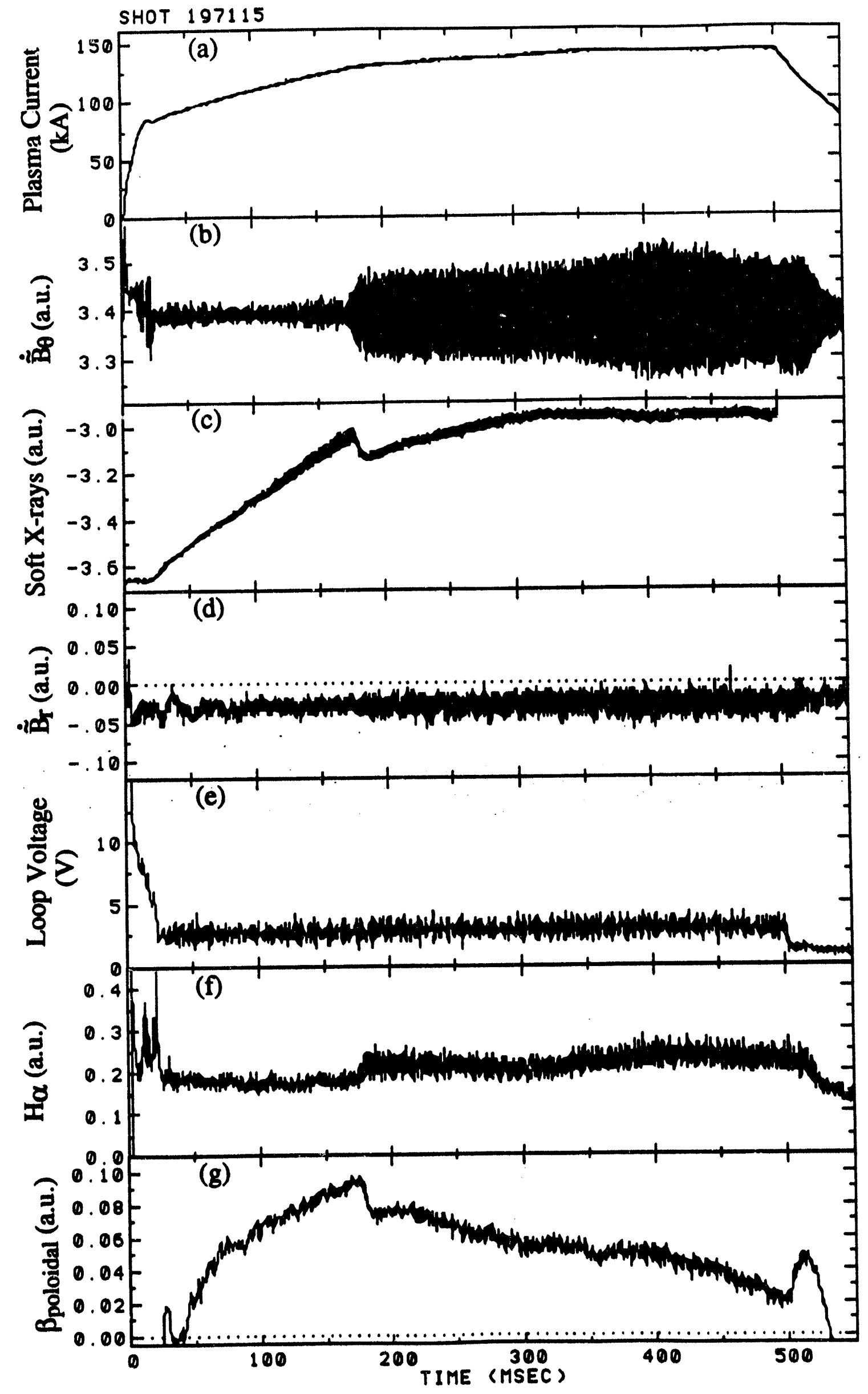

Fig. 11 


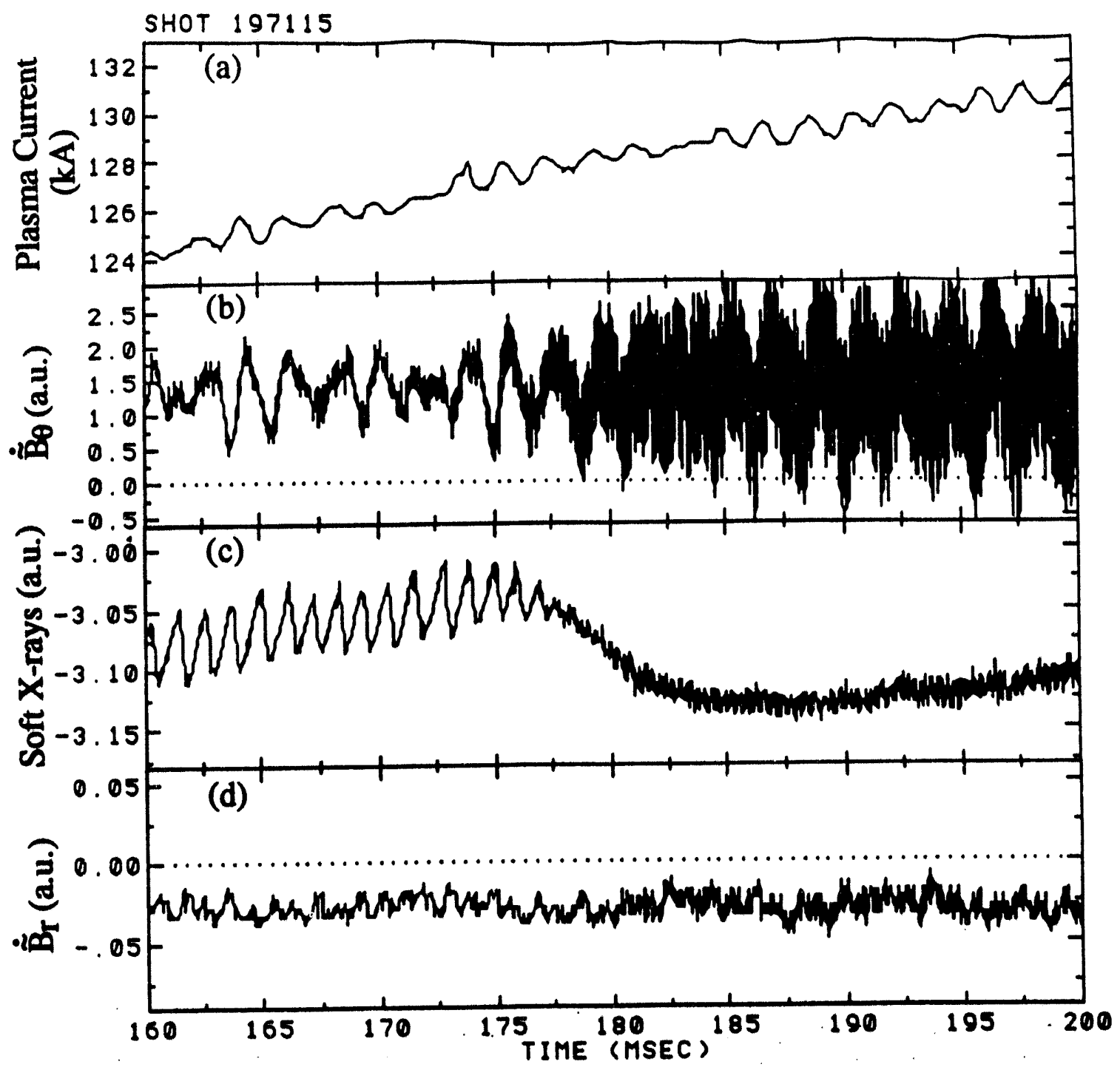

Fig. 12
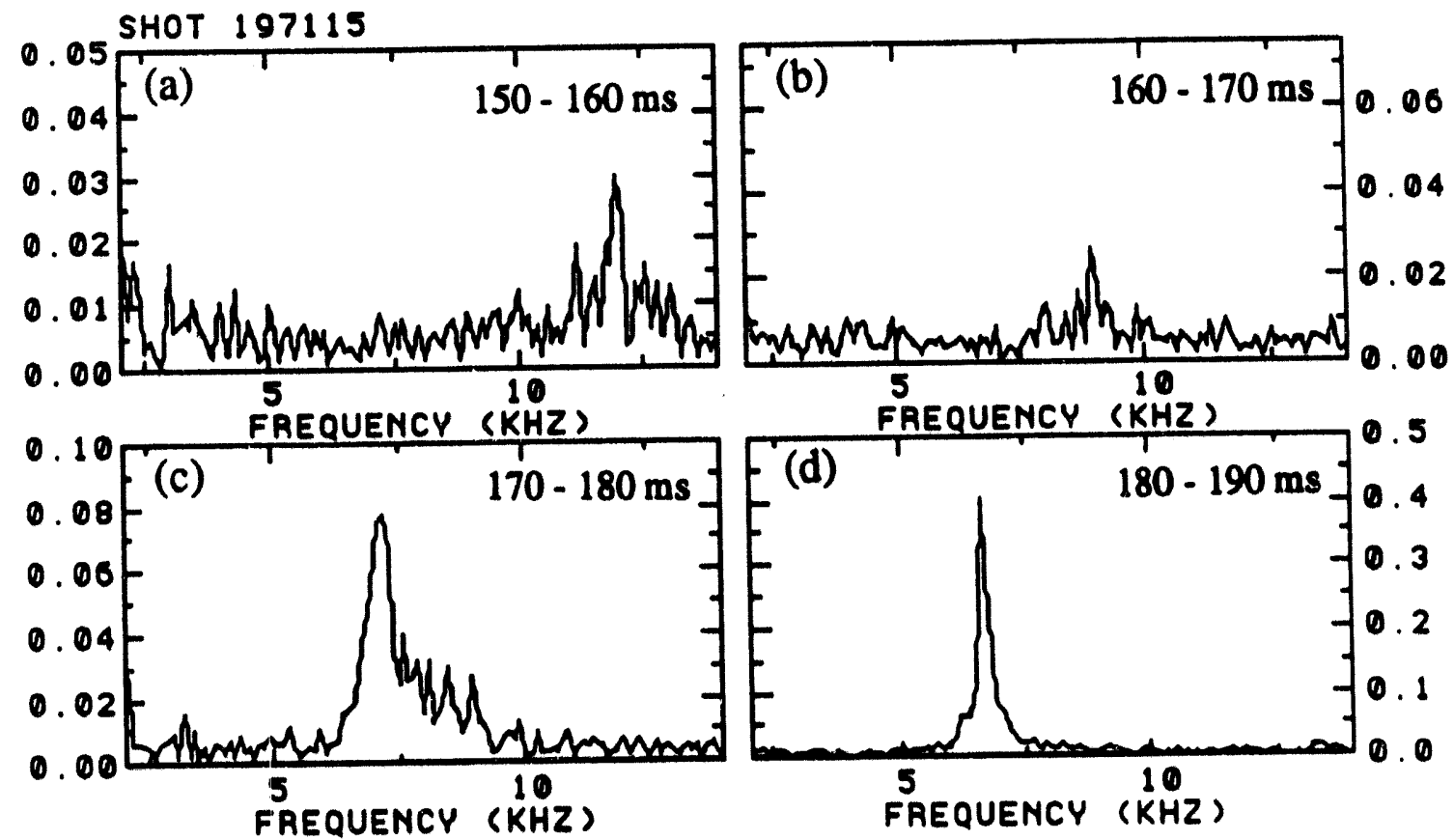

Fig. 13 

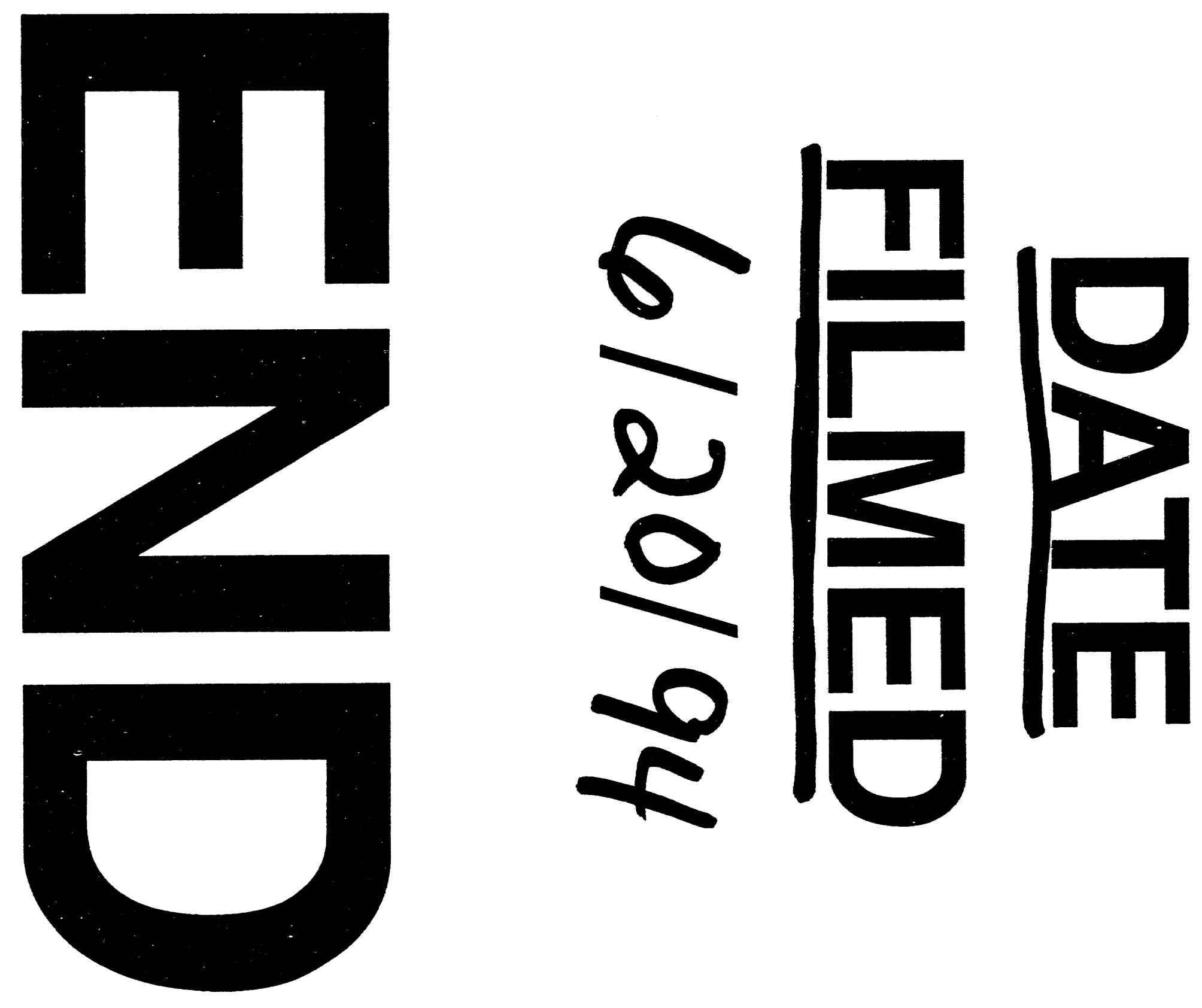
